PN

DOI Number: 10.30520/tjsosci.511216

\title{
ESKİ MISIR KRALLIK DÖNEMLERINNDE SANAT VE MÜZİK KÜLTÜRÜ ÜZERİNE KISA BİR İNCELEME
}

\author{
A BRIEF OVERVIEW OF ART AND MUSICAL CULTURE IN KINGDOMS TIME OF \\ ANCIENT EGYPT
}

\author{
Ganire HÜSEYNOVA ${ }^{1}$
}

\section{ÖZET}

İlk Çağ uygarlıklarının ortaya çıktığı Doğu toprakları dünya medeniyetinin beşiği kabul edilmektedir. Dünya kültürünün oluşumuna önemli katkı sağlayan uygarlık merkezlerinden biri de Akdeniz bölgesidir. Bu coğrafyanın doğal zenginlikleri ve sosyal şartları ilk uygarlıkların doğmas1 için uygun bir zemin oluşturmuştur. Geçmişten bizlere miras kalan en büyük medeniyetlerden birisi hiç şüphesiz, Eski Mısır uygarlığıdır. Mısır medeniyeti özgün ve yenilikçi yapısıyla komşu kültürlerin çok önünde yer almıştır. Birçok tarihi belgeler ışığında çevre devletlerin zengin Mısır kültüründen etkilendiği anlaşılmaktadır. Mısır uygarlığı eski olmakla birlikte, krallık dönemleri ve zaman içindeki sürekliliği ile de ilgi çekmektedir. Mısır toplumunun yaşamında önemli bir yer tutan müzikal eylemler, ayin dansları tarih öncesinden süregelen eski inanç etkisi varlığının açık bir göstergesidir. Diğer eski doğu medeniyetlerinde olduğu gibi, müziğin şiirle ve dansla yakın bağlantısı Mısır kültürünün başlıca özelliklerinden sayılır. Eski Mısır drama gizemlerinin kökenleri buradadır. Yapılan araştırmalar sayesinde bu coğrafyada kullanılan çalgıları tanımayla birlikte, çalgıların detaylı incelenmesi sonucu dönem müziğinin özellikleri ve karakteri hakkında bilgiler elde emek mümkün olmuştur. Dönemler ilerledikçe, sanat ve müzik alanında gelişimlerle birlikte, kültürün tamamen farklı bir duruma doğru yöneldiği görülmüştür.

$\mathrm{Bu}$ araştırmada, İlk Çağ uygarlıkları bağlamında Eski Mısır'ın krallık dönemlerindeki sanat ve müzik kültürü üzerine incelemeler yapılmış, toplum üzerindeki etkisi ve işlevinden söz edilerek amaçlarına değinilmiştir. Krallık dönemlerine ait sanat, müzik türleri ve çalgılar hakkında genel bilgiler verilerek, Mısır medeniyetinde dans ve müziğin kullanma şekilleri, dinsel ve günlük yaşamdaki rolleri açıklanmaya çalışılmıştır.

Anahtar Kelimeler: Mısır Kültürü, Krallık Dönemleri, Müzik, Ritüel Danslar, Çalgılar

\footnotetext{
${ }^{1}$ Doç. Dr., Erciyes Üniversitesi, Güzel Sanatlar Fakültesi, Müzik Bölümü, ganira@erciyes.edu.tr
} 
ABSTRACT

The eastern lands, where the first civilizations arose, are considered the cradle of world civilization. One of the centers of these civilizations, which made a significant contribution to the formation of world culture, is the Mediterranean region. The natural wealth and social conditions of this geography provided a suitable basis for the emergence of the first civilizations. One of the greatest inherited from the past is undoubtedly the ancient Egyptian civilization. Egyptian civilization differed from neighboring cultures with its original and innovative structure. In the light of many historical documents, the influence of the rich Egyptian culture on the surrounding states is noticeable. Together its antiquity, it also attracts attention with periods of the kingdoms and continuity in time. Musical acts that occupy an important place in the life of Egyptian society, and ritual dances are vivid evidence of the existence of the effect of the old faith that existed since prehistoric times. As in other ancient Eastern civilizations, the close connection of music with poetry and dance is considered to be the main feature of Egyptian culture. Here also is the origins of the ancient Egyptian drama. With the help of the research, it was possible to recognize the musical instruments of those times, and also as a result of a detailed study of the instruments, to obtain information about the features and character of the music of that time. Over time, along with developments in the field of art and music, culture takes on a slightly different character.

In this paper, in the context of the first civilizations, studies were conducted on the art and musical culture of the ancient Egyptian kingdoms, defining their goals and functions. The purpose of this course is to give general information about the arts, musical genres and instruments belonging to the kingdom period, and to explain the use of dance and music in Egyptian civilization, their role in religious and everyday life.

Keywords: Egyptian Culture, Kingdom Periods, Music, Ritual Dances, Musical Instruments

\section{GİRIS}

Uygarlıkların kültür tarihine ilişkin araştırmalar antropoloji, arkeoloji ve etnomüzikoloji konularıyla doğrudan bağlantı göstermektedir. Günümüzde eski Mısır coğrafyasında sınıflaşmadan önce kültürel evrimin Paleolitik ve Neolitik çağ aşamalarından geçtiği bilinmektedir (Bard, 2015: 71). Bölgedeki arkeolojik kazılarda bulunan kemik ve taştan yapılmış kaba araçlar, toplumun erken gelişim çağında iş bölümü ve grup evliliklerin (group marriage) eski insanların yaşam biçimini ne kadar etkilediğini ortaya koyar (Massey, 2005: 79). Bu zaman diliminde ortaya çıkan manzara, savaşlar sonucunda gelişen sınıflı toplum ve köleliğin var olduğu zengin imparatorluklardır. M.Ö. 5000'lere gelindiğinde farklı kabile ve diller karışımından nome ${ }^{2}$ adlı site devletlerin oluştuğu kaydedilmiştir (Denham; Iriarte; Vrydaghs, 2016: 372). M.Ö. 4000'lerin ortasına doğru küçük sitelerin birleşimi sonucu muhteşem ve güçlü Mısır devleti meydana çıkar. Böyle egemen bir merkezi devlet sisteminin oluşmasında Nil nehrinin civarı uygun şartlar taşıyan bir konum olmuştur. Uygarlık düzeyi komşularından çok önde olan Mısır, muhteşem ve dev yapıtlarıyla tanınır. Piramitler, gizemli sfenksler, firavun ve tanrılar şerefine yapılan tapınaklar Eski Mısır kültürünü en iyi yansıtan simgelerdendir. Mısırın potansiyelini aksettiren bu simgeler komşu devletler karşısında ona büyük otorite kazandırıyordu.

\footnotetext{
${ }^{2}$ İlk zamanlarda şehir devletlerinden oluşan ülkeler
} 
Akdeniz kıyısının ilk uygarlıklardan olan Mısır, Eski (M.Ö. 2625-2130), Orta ( M.Ö. 1980-1630) ve Yeni Krallı (M.Ö. 1539-1075) (Christensen, 2009: 120) olarak üç büyük imparatorluk dönemine ayrılmaktadır. Bu krallık dönemlerinin her birinde devletin politika, bilim, eğitim, sanat ve mimarisinde büyük ilerlemelerin olduğu kaydedilmiştir. Bu anlamda, periyotlara ait sanat, müziğin yapısı ve çalgılar hakkında bilgilerin ilk, belki de en önemli kaynağı firavun tapınaklarında ve mezarlarında bulunan eşyalar, papirüsler üzerindeki metin ve tasvirler olduğu söylenebilir. Bunun yanında, Mısırlıların yaşam tarzı, örf ve adetleri, ritüelleri hakkında önemli bilgiler edinilmesinde Antik Yunan ve Roma yazarlarının eserlerindeki betimlemeler büyük katkı sağlamaktadır.

Son derece köklü Mısır uygarlığı, şüphesiz araştırmaya değer bir yapıya sahiptir. Bu çalışmada çeşitlilik bakımından Eski Mısır'ın Krallık dönemlerindeki sanat ve müzik kültürü kavramı incelenmeye alınmıştır. Akışın daha kolay izlenmesi açısından krallık dönemleri ayrı ayrı başlıklarda düzenlenmiş, sonuç kısmında elde edilen bulgulardan tartışmalar öne sürülmüştür. Belirsizliği önlemek için, yabancı adlandırmalar ve terimler yerinde kesme işareti kullanılarak italic yazı türü ile belirtilmiştir.

\section{Eski Krallık Döneminde Sanat ve Müziğin Karakteristiği}

Genel olarak, Mısırlıların yaşadıkları ve yaşattıkları her şeyi resimlendirme gibi ilginç bir alışkanlıkları olmuştur. Arkeolojik kazılarda bulunan görsel kaynaklar eski Mısır kültürüne ilişkin bilgi edinmesi bakımından önemli bir etmendir. Tarih öncesi çağlara ait kaya resimleri, çanak-çömlek ürünleri üzerindeki çizimler, Mısır kültüründe geniş ölçüde etkili müzik ve dans geleneği olduğu bilgisini tanımlamakla birlikte, o dönemde resim sanatının çok geliştiği düşüncesini destekleyen ana unsurlardandır.

Saray etkinlikleri, kutlama ve törenler, savaşlar hep müzik eşliğinde gerçekleştirilmiştir. Müzik, eski Mısır'daki dini ibadetin ayrılmaz bir parçasıydı, bu yüzden tanrıları müzikle tezahür edildiği şaşırtıcı değil. Misırlılarda dansların büyülü güce sahip olduğu hususundaki inanç özellikle vurgulanmalıdır. İlkel kabilelerden başlayarak insanların iç dünyaları ve inançları etkisiyle yaptığı büyülü ayin dansları, ilk uygarlık dönemlerinde de devam etmiştir (Lexová, 2012: 42). Toplum için büyük önem taşıyan bu ritüel dansların esas amacı üretimi desteklemek olmuştur. Ekim ve hasat döneminde çiftçilerin vazgeçilmezi olan bu danslar aşağıdaki tasvirden anlaşılmaktadır:

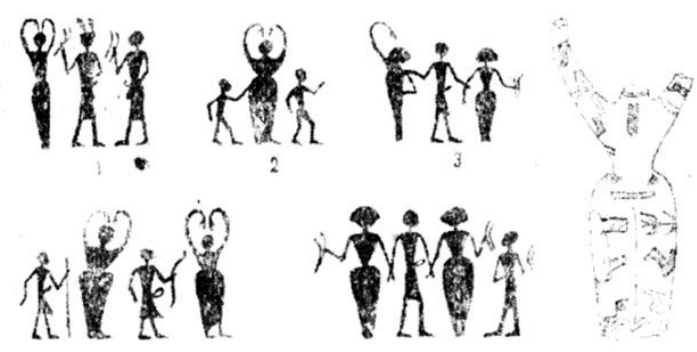

Resim 1. Kaynak: Gruber, 1941:169

Resim 1de hanedanlık öncesi Mısır'da ellerinde bitki dalları tutarak crotale ${ }^{3}$ eşliğinde dans eden kadınlar tasvir edilmiştir. Sağda büyük tanrıçanın heykelciği bulunmaktadır

\footnotetext{
${ }^{3}$ Basit bir vurma çalg1
} 
(Gruber, 1941:169). Bu belirtiler, aynı zamanda arkaik Mısır kültündeki anaerkil unsurların başka bir doğrulamasını ortaya koymaktadır. Benzer görüntüleri "Toprak Ana" tezahürü olarak yorumlamak mümkündür. Flüt eşliğinde mahsul toplanması, bu çalg1 sesinin büyüleyici bir etkiye sahip olduğu inancından kaynaklanmıştır (Gruber, 1941:173). Aşağıda (Resim 2.) bu sahnelerden biri tasvir edilmektedir:

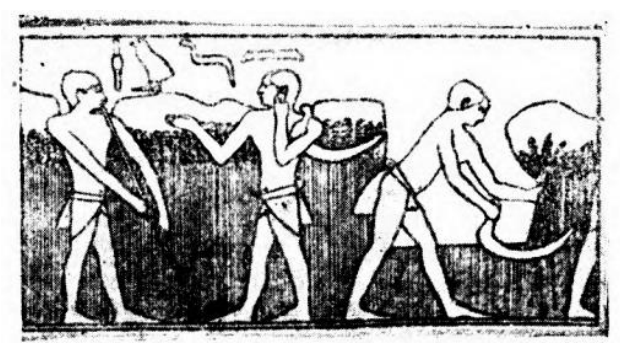

Resim 2. Kaynak: Gruber, 1941:173

Bununla insanlar müzik ve dans etme eylemlerinin bolluk ve bereket getireceğine inaniyordu.

Günümüze kadar ulaşan tasvirler arasında av için yapılan büyü dansı dikkat çekicidir. Tarihi M.Ö. 4000'lere ait edilen bu çizimde, temsili zürafa, öküz ve koç arasında flüte benzer çalgıyla tilki kılığına girmiş kişi görülmektedir:

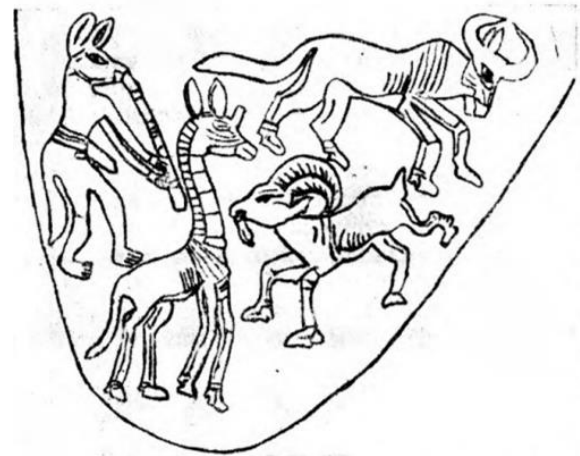

Resim 3. Kaynak: Gruber, 1941:172

Ayin dansları, bir bakıma "müzikal illüzyon" nitelikli bir sanatsal ifade aracı olduğu söylenebilir. Böyle "müzikal illüzyon" örneğinin bir diğeri de üzüm suyu üretimi sırasında işçilerin ayak ritimlerine tokmaklarla eşlik etme sahnesinde betimlenmiştir:

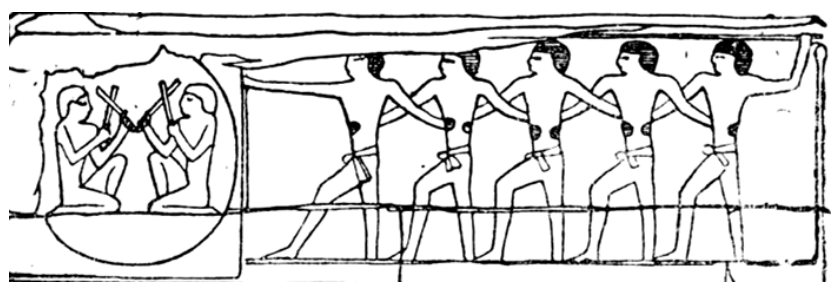

Resim 4. Kaynak: Gruber, 1941:172

Eski dönemi anlatırken müzikal ifade dilinde önemli bir bölünmezliğin hâkim olduğunu belirtmek yerinde olacaktır. Buna birkaç örnek göstermek gerekirse: hem şarkıcı, hem de ellerini çırparak şarkıya eşlik eden (Resim 5a) aynı hiyeroglifle yazılırdı: 


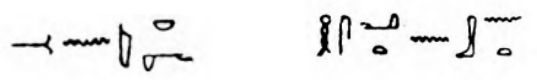

Resim 5a.
Resim 5b.

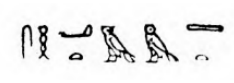

Resim 5c.

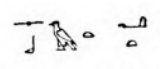

Resim 5d.

Kaynak: Gruber, 1941:173

Yine örneklerle devam edecek olursak, arp çalmak ve arp eşliğinde şarkı söylemek (Resim 5b), obua çalmak ve obua eşliğinde şarkı söylemek (Resim 5c), flüt çalmak ve flüt eşliğinde şarkı söylemek (Resim 5d) de aynı hiyeroglifle anlamlandırılmaktaydı. Ayrı dönemlerdeki önemli değişikliklere rağmen, bu karakteristik özellikler eski Mısır müziğinin tarihi boyunca sürmüştür.

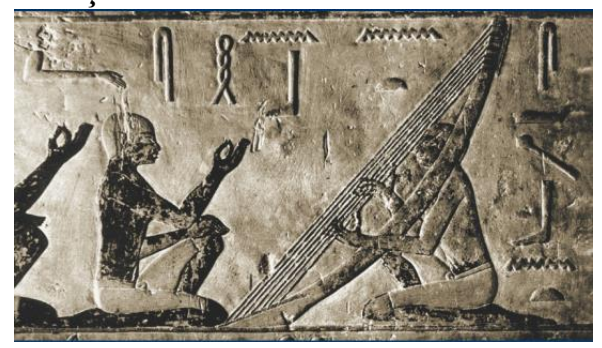

Resim 6. Şarkıcıya eşlik eden arpçı. V hanedanının Mezarı (Sakkara nekropolü). Kaynak: https://bigenc.ru/world_history/text/1975690

Eski Mısır'da yaşamın her alanında, halk sanatından saray ve tapınak ayinlerine kadar müziğin muazzam rolünü keşfetmek hiç de zor değildir. Müzik daima hem asillerin, hem de alt kesimlerin günlük yaşamında önemli bir yer tutmuştur. Sosyal hayatta önemli bir yer işgal eden sanat, aynı zamanda iktidar sınıf tarafından kontrol edilmiş, çalgıların yapımı dâhil, törenlerin organizasyonunda koro, dans ve çalgıcıların programı sık1 bir denetim altında tutulmuştur. Toplumun önemli bireylerinden sayılan müzisyenler sosyal seviyelerine göre sınıflandırılmaktaydı. Görünüşe göre tapınak müzisyenleri en yüksek statüye sahip olmuşlar. Bir alt grubu saray müzisyenleri oluşturmaktaydı; saray hiyerarşisinde yüksek mertebelerde yer alan müzik yönetmenleri, şarkıcılar, çalgıcılar firavuna resmen bir akraba sayılmışlar (Shindina, 2009: 6). Bu sadakat, aynı zamanda firavun mezarlarına koyulan eşyalar arasında sanatçı tasvirli nesnelerin bulunmasıyla da desteklenebilir. Mısırlıların inancına göre resimlerdeki çalgıcılar, şarkıcılar, dansçılar hükümdarlarını öte dünyada da eğlendire bilecekti. "Sosyal merdivenin" alt basamağında, genellikle kutlama ve törenlerde müzik yapan sanatçıların olduğu bilinmektedir.

Diğer taraftan en eski dönemlerden beri Mısır'da hükümdarın bir tanrı olduğu inancı izlenmiş, iktidarın tek kaynağı firavunlar doğuştan tanrıların selefleri olarak kabul edilmiştir. Tanrı-firavun otoritesini tanıyan Mısırlılar, ezelden beri tanrıları varlığın ilk nedeni olduğunu, daha sonra bu güç ve kudretlerinin hükümdar ve firavunlara geçtiğini kabul etmişlerdir. Bu anlamda tapınak görüntüleri firavunun tanrısal kökeninin olduğu düşüncesini vurgulamaktadır (Jak, 20008: 71).

Eski Krallık dönemine ait müziğin karakteristiği dinsel cenaze müziği, mezarlar ve piramit kültürüyle bağlantı içinde olduğu söylenebilir. Dönemin müziğine ait en zengin belge kaynağı elbette piramitlerdir. Piramit duvarlarındaki yazılarda cenaze merasimlerinde (Resim 7.) yapılan ayinin tamamı kaydedilerek, törenin kaç kez ve hangi şekilde uygulanacağı bilgileri verilmekteydi (Gruber, 1941: 174). Kaydedilen bu veriler, uzak geçmişte kült müziğinden doğan ayinlerin mevcutluğunu netleştiren somut 


U

bilgiler olarak, doğu kültürünün erken Hıristiyanlığın başlarına kadar devam edeceğini belirlemektedir.

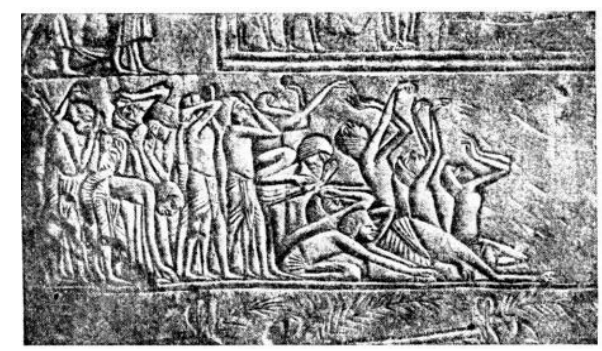

Resim 7. Ölen kişiye yakılan ă̆ıt Kaynak: Gruber, 1941:174

Müzik sadece eğlencelerde ve matem törenlerinde değil, tüm sosyal alanlarda yaşamını sürdürmüştür. Kültsel müzik, jest hareketli danslar ve şiirin bir arada sergilenmesi eski Mısır kültürünü karakterize eden başlıca özelliklerdendir. Zira müzik, söz sanatı ve beden dili birlikteliği ayrılmaz bir bütün haline getirilebilmişti. Birliktelik karakteri bölgedeki diğer halkların (Koptlar, Habeşler, Bedeviler) kült ezgilerinde de sezilmektedir (Gruber, 1941:173). Bu ezgilerin yakınlık olasılığı, yerel halkın yaşamı, dili ve inançlarının benzerliğiyle dikkat çekiyor. Eski Mısır kültürünün zengin dağarcığını oluşturan saray ve tapınak müziği bu tür kült karakterli ezgilerle sınırlı kalmamıştır.

Eski Krallık Döneminde "şeflik” sanatı “olduğu kanısı da güçlüdür. Ellerle yönetme eylemi cheironomy ${ }^{4}$ (Resim 8.) toplu gösterilerin vazgeçilmezinden sayılmıştır (Lind , 2012:110). Çoğunlukla şarkıcılar eşlik eden müzisyenler için cheironomist görevi yapmışlar. Ellerle yönetim birkaç seriden oluşmaktaydı. İyi araştırılmış bir cheironomy serisi için aşağıdakiler söylenebilir: temel ton elin baş ve işaret parmaklarının kilitlenmiş halka görüntüsü ile belirtilirdi; Beşli aralık (quinta), öne doğru açılan elin parmaklarını uzatarak sıkılmasıyla ifade edilmiştir. Ara tonlar, el ve parmakların farklı açılardan eğilmesiyle gösterilmekteydi. Ne yazık ki, bu gözlemler, eski Misır müziğinin ses dizimi ve tonalitesini tespit etmek için yeterli olmamıştır (Kaznelson, 1976: 418).

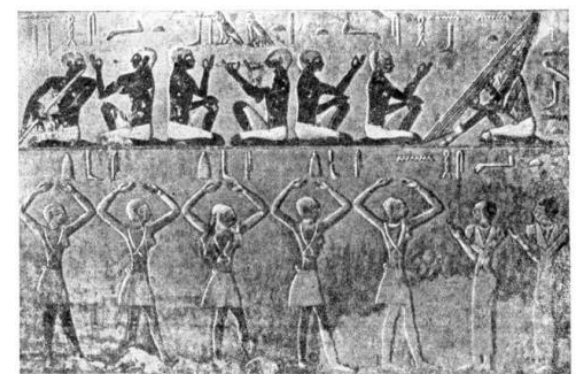

Resim 8. Şarkıcı cheironomy'stler, flütçü, obuacı, arpçı ve dansçılar (Eski Krallık dönemine ait duvar kabartması, M.Ö. 2700). Kaynak: Gruber, 1941:175

\footnotetext{
${ }^{4}$ Şarkı söylemede ritim, dinamik işaretler ve karakteri belirten şartlı el hareketleri
} 
Duvar tasvirlerinde sıkça resmi saray kutlamalarına rastlamak mümkündür. Kahire müzesinde sergilenen yarım kabartma üzerindeki şarkıcı, çalgıcı ve dansçıların tasviri, Eski Mısır kültürüne özgü sentezi burada da hissettirmektedir. Dansçıların flüt ve arp eşliğindeki ağır hareketleri, saray ve tapınak müziğinin şaşaalı tarzını yansıtmaktadır (Gruber, 1941:175).

Eski krallık döneminde sanatın düzeyini açıklığa kavuşturmak açısından firavun saraylarındaki cücelerin faaliyetini bir başka örnek olarak göstermek yerinde olacaktır. Rus sanat tarihçisi Turayev konuyu şöyle açıklar: “Tropik Afrika'nın Büyük göller bölgesinde yaşayan kısa boylu insan kabilelerinden seçilen bu cüceler dansçılık ve soytarılık yapmak için firavun saraylarına getirilirdi. Saray ortamını canlandıran bu cücelere çok değer verilirdi. $\mathrm{Bu}$ anlamda, piramit duvarlarındaki "padişahın tanrıların yanındaki yaşamı, cüce dange'nin saraydaki yaşamı kadar iyidir" yazısı, bir bakıma cücelerin saray yaşamındaki durumunu destekliyor olmasıdır (1935: 179)". Bu, modern düşüncede müzikali temsil eden bir eylem olarak değerlendirilebilir. Buradan da anlaşıldığı gibi, Eski Krallık döneminde saray ve halkın müzik kültürü çoğunlukla uygarlık öncesi kültürün izlerini taşımaktaydı. Aksi hâlde cücelerin bayağı dans ve müziği bu kadar ilgi odağı haline gelmezdi.

Çalgılara gelince, tasvirler dikkatli incelendiğinde, müzisyenlerin ellerini tutuş ve konumuna göre bir takım çıkarımların yapılması kolaylaşmaktadır. Söz gelişi üfleme çalgılar üzerindeki ses delikleri ve telli çalgılarda tellerin kalınlığı ile uzunluklarının oranı, dönemin ses dizisi karakteristiğinin belirlenmesine az da olsa yardımc1 olmaktadır. Deliklerin yeri ve sayısı, bazı kabilelerde pentatonik kalıbın kullanıldığ hipotezini destekler niteliktedir. Lir ve arplarda tel sayısı, burguların konumu, ellerin tutuş şekli ise o dönemde "kromatik - enharmonik" (Resim 9.) ses dizimi olduğu ihtimalini kuvvetlendirir (Gadalla, 2017: 2). Pentatonik perdelerin kromatik basamaklarla kurulması bir nevi "modülasyon" oluşumuna olanak vererek, Kurt Sachs'ın bu konuda "sekizli, beşli, dörtlü ses aralıkları birlikte basabilme" savını destekler. Görünüşe bakılırsa, Misırlılar kendilerine özgü bir sistem geliştirdikleri ortadadir.

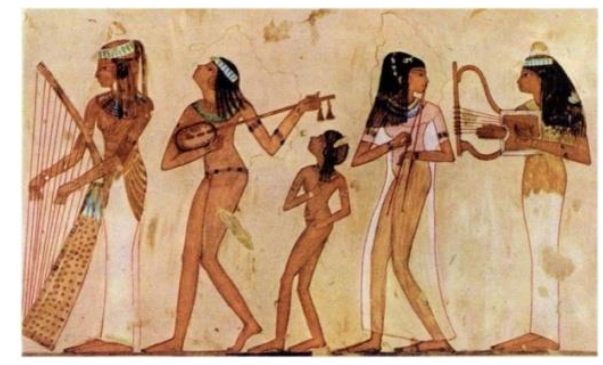

Resim 9. Kaynak: http://drevniy-egipet.ru/muzyka-drevnego-egipta-osobennosti/

1960’larda Sovyet bilim adamı A. Machinsky Eski Mısır ses sisteminin incelenmesine yönelik çalışmalara başlar. Machinsky'nin araştırma sonuçlarını etnograf Pomeranceva şöyle aktarmıştır: "Bazı çalgı ölçülerinin doğruluk derecesi yeterince net bir görüntü üzerinden aktarıldığ 1 düşünülürse, bunların tel uzunluğu ölçülerek, en uzun tele göre oranını hesaplamak gerekecektir. Daha sonra, birkaç aynı tip çalgı görüntüsü üzerinden tel uzunluklarının ortalaması çıkarılacaktır. Elde edilen veriler karşılaştırılarak, eski Mısır müziğinin müzik sistemlerinden herhangi birine yakınlığı tespit edilebilir. 
Machinsky'nin, yaptığı hesaplamalar üzerinden eski Mısır müzik sisteminin İskoç ya da Çin ses dizisine yakın olduğunu, bunun yanı sıra, başlangıçta (Eski Krallık döneminde) aralıkların bir ses olduğu, daha sonraları ise (Yeni Krallık döneminde) bu sistem bozulmadan yarım ses aralıklarının kullanıma girdiği tahmin edilebilir" (Pomeranceva, 1976: 18).

Bütün bunların yanında bu kadar kültür zenginliğine sahip Mısırlıların yazılı müzik örnekleri bırakmamış olması, gerçekten üzücü bir durumdur. Zira Mısır kültürü araştırmalarında müzikal bileşenleri tanımlayan nota, şifreli yazı, işaret gibi yazılı kaynaklar bulunamamıştır. Oysa müziğin yayılmasında önemli rolü olan çok sayıda müzisyen tasvirleri yanında notasyonların yokluğu bir paradoks yaratmaktadır. Görünüşe göre bu, kült müziğinin kaydedilmesine konulmuş olan mistik tabularla bağlantılıdır. Eski Misırlılar, Greko-Romen dönemine kadar müziklerini kaydetmedikleri için (Braudo, 2014: 7), firavunlar dönemine ait müziği yeniden yapılandırma girişimi konusunda spekülatif düşüncelerden kaçınılmalıdır. Öte yandan Doğu kültüründe müzik sanatı genellikle usta-çırak ilişkisi üzerine kurulduğundan notaya dökülmüş kaynağın bulunmaması çok da şaşırtıcı değildir. Müzikal yazıya ilişkin bazı işaretlere yalnız Orta ve Yeni Krallık dönemine ait metinlerde rastlanmıştır (Gruber, 1941:179). Bu zaman diliminde piktografik işaretler, resimsel notasyon ve kozmoloji üzerine ilk eserlerin ortaya çıtığı bilinmektedir.

\section{Orta Krallık Döneminde Başlıca Sanatsal Atılımlar}

Eski Krallık döneminin sonuna doğru sanatın tamamen yeni bir boyut kazandığ1 görülmektedir. $\mathrm{Bu}$ bakımdan, Orta Krallık dönemine ait mimari, heykel, tapınak resimlerindeki üsluplar, kültürde değişim ve ilerlemelerin arttığını kanıtlar niteliktedir. $\mathrm{Bu}$ dönem için etik gelişimi sağlayan sanat, müzik, edebiyat toplumun sosyal yaşamının vazgeçilmez temel unsurlarından olmuştur. Diğer taraftan geometri, astronomi, tıp bilimi alanındaki hızlı gelişmelerin yanında söz sanatına özgü macera hikâyeler, masal ve destanlar gibi yazılı kaynakların ortaya çıkması, dönemin bilim ve sanat hakkındaki düşüncelerin genişlemesine yardımcı olmaktadır.

Eski Krallık dönemiyle kıyaslandığında, Orta Krallıkta muazzam bir kültür atılımlarıyla karşılaşmaktayız. Özellikle dans sanatında üst düzey teknikler, gerçek akrobatik hareketler göze çarpmaktadır. Bazı resimlerde (Resim 10.) dansçıların bacaklarını, kaldırılmış kol seviyesinin üzerine çıkardığını görmek mümkündür. Hareketlerdeki bu esneklik ve serbestlik, aynı zamanda düzenlilik karakteristiği, süreklilik ve simetrisiyle de dikkat çekicidir.

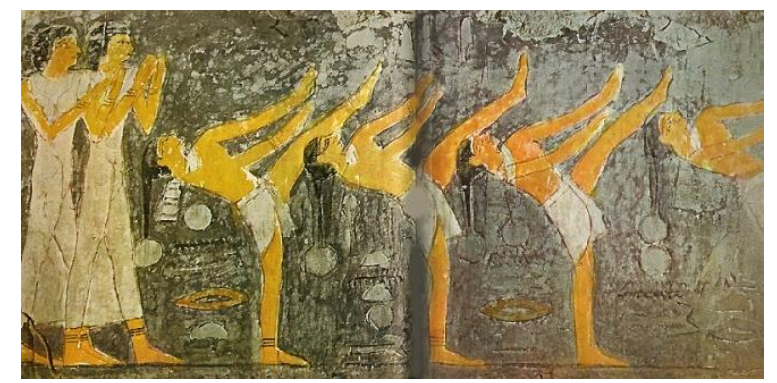

Resim 10. Akrobatik danslar. Mehu'nun Mezarı (Sakkara nekropolï). Kaynak: https://sites.google.com/site/danceinegypt/images/ancient-times-till-400-ad 


U

Tasvirlerde sıkça rastlanan berberi raksları, Libyalı, bedevi ve diğer halkların savaş dansları (Resim 11.), aynı zamanda etnik azınlıkların Mısır toplumuna nüfuz ettiğine işaret etmektedir.

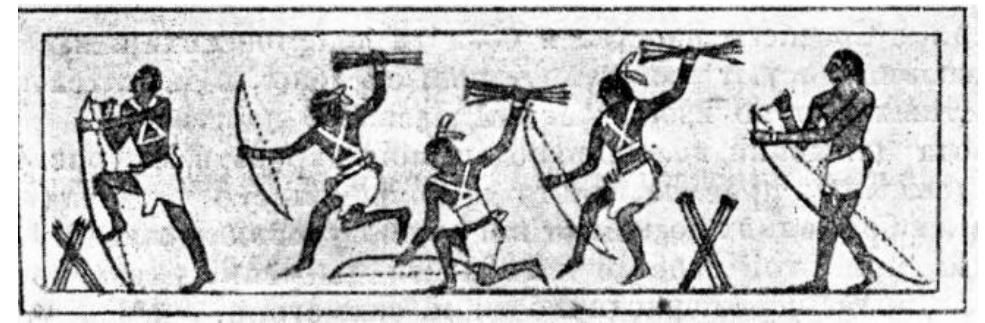

Resim 11. Bedevilerin dansı. Tel el-Amarna rölyefi. Kaynak: https://studopedia.info/8-56438.html

Sosyal mübadeleler sonucu müziğin de köklü değişime uğraya bileceğini söylemek yanlış olmayacaktır. Kuşkusuz, dans, söz ve müzik sanatının sentezi, icrasal müziğin karakteristiğini yakından etkilemesi kaçınılmazdı. Dönem çalgılarından arp, flüt ve lute'nin diğerlerine göre daha popüler olduğu söylenebilir (Gadalla, 2017: 3-4). Bu varsayım, tapınaklarda sıkça görülen arpçı, flütçü, şarkıcı ve dansçı resimleri yönüyle doğrulanmaktadır. Bunların arasında tarihi M.Ö. 6000 yıllarına ait edilen arp tasvirleri, bu çalgının hiyeroglifler ortaya çıkmadan ve tapınaklar yapılmadan çok daha önce var olduğunu ortaya koymaktadır. Alt sınıflar çoğunlukla lir çalgısı kullanırken, üst kesimlerin bulunduğu saray ve tapınaklarda arp önemli derecede üstünlük göstermiştir. Çizimlerde arpların küçük, elde tutup dolaşarak çalınandan, dini törenlerde kullanılan insan boyundan yüksek olan (Resim 12.) çeşitlerine rastlanmıştır (Gruber, 1941:173). Mısır'da arp bir zarafet simgesi olarak kabul edilmiş, ressamlar birçok tanrılarını arp çalarken tasvir etmişler (Grigorenko, 2008: 36-37). Bu bakımdan, Eski Mısır müziğini araştıran birçok bilim insanı, Mısırı arpın anavatanı olarak kabul etmektedir.

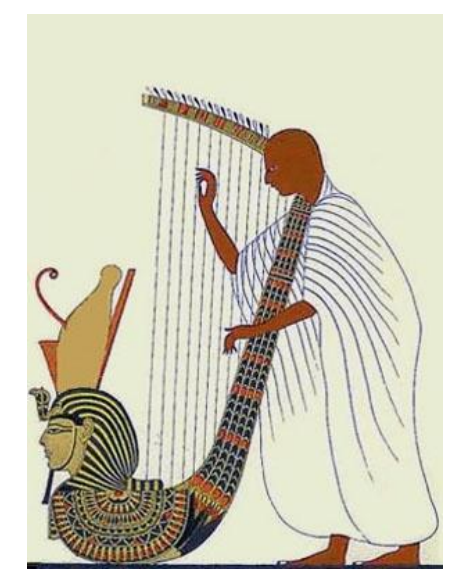

Resim 12. Kaynak: http://travelingwithintheworld.ning.com/profiles/ancient-instruments

Orta Krallık döneminde Asya'dan getirildiği tahmin edilen köşeli arplar toplumda pek rağbet görmüsşür. Bu arpların üstünlüğü diğerlerine göre akortlanması daha kolay, gür ve net bir ses tınısına sahip olmasından kaynaklanıyordu.

Misırlılar arp ve flüte göre lute çalgısıyla daha geç bir dönemde tanışmışlar. Bazı tarihçiler lute'nin yayılmasını, XVIII. Hanedanlık döneminde Mısırlıların fethi sonucu 
artan Asya kültürünün etkisi ile ilişkilendirmektedir. Akdeniz boyunca geniş alana yayılmış spesifik sistrum ${ }^{\mathbf{5}}$ çalgısının, özellikle bu dönemde Mısır kült müziğinde uygulandığını antrparantez belirtmek gerekir (Gruber, 1941: 180).

Orta Krallık döneminde önemli kültürel gelişmelerden biri de dram sanatında yaşanmıştır. Tanrı Osiris ${ }^{6}$ şerefine yapılan gösterilerin geçmişi, sosyal sınıflaşma öncesine kadar gitmektedir. Özellikle, kışın başında Mısır'ın on altı büyük kentinde yapılan "Osiris tutkuları" adlı gösteriler büyük ilgi görmekteydi. Osiris' in yaşadığı 1stırapları anlatan "gizemleri" 7 Herodot $^{8}$ Sais'te bizzat kendisi izlediğini eserlerinde anlatmıştır (Gruber, 1941: 181). Heyecan verici sahneler Gruber tarafindan şöyle anlatılmaktadır: "Rahip ve rahibelerin oynadığı gizem gösterilerine seyirciler de katılma imkânı bulabilmekteydi. İlk sahnede yüzlerce insan toprak, tahıl, tütsü ve kıymetli taşlardan iki tanrı heykeli yapar. Heykellerin yanı başında yas kıyafetleri giymiş, dağınık saçlı Isis ve Nephthys durmaktalar. Sıradan halktan oluşan izleyici kitlesi, maskeli oyuncuların söylediği ağıtlara destek vererek, rol gereği tanrı ve tanrıçaların acısını paylaşırlar. İnsanlar ağlayıp dövünerek, Osiris' $i$ yeni bedeninde hayata dönmeye seslerler. Gösterinin en heyecanlı yeri ve tutkuların kabardığ 1 son "yeniden doğuş" sahnesidir; büyülerle Osiris yeniden hayat kazanır. Orta Krallık Döneminin sonlarında "Osiris tutkuları" gösterisine "Isis gizemleri" adlı kült eyleminin birkaç sahnesi dahil edilir. Isis kutlamaları genellikle ilkbahar ve sonbahara adanarak yorumlanmıştır" (1941: 181). Osiris efsanesi, bir bakıma Hıristiyanlığın temelindeki "Ölen ve Dirilen Tanrı" kavramıyla karşılaştırılabilir düzeydedir. Diğer taraftan, "Osiris tutkuları"ndaki bu kitlesel demokrasi, belki de her bir Misırlının Osiris'in imgesinde ölen akraba ve yakınlarının dirilişini umarak gözyaşı döktüğü olarak açıklanabilir.

Bir diğer yaygın kültürel unsurlardan olan masal okuma sanatı toplumun büyük ilgisini çekmiştir. Kalabalık içindeki meraklılar, hikâyecilerin her seferinde yeni eklemeler artırarak anlattıkları masalları hevesle dinlemişlerdir (Gruber, 1941: 181). Benzer eylemler, aynı zamanda Orta Krallık Döneminde estetik sanat kültürünün bu tür kült gösterileri ile birlikte geliştiği düşüncesini de açığa vurmaktadır. Yukarıda söylenenleri dikkate alarak yüzyıllar sonra antik dramı oluşturan mimik ifade sanatı, tiyatro, trajedi, komedi gibi unsurların ilk temellerinin Mısır'da atıldı̆̆ı, buranın bir çıkış noktası olduğu kabul edilebilir.

\section{Yeni Krallık Dönemi Sanatında Önemli Değişikler}

Yeni Krallık dönemi Eski Mısırın tarihinde siyasal ve kültürel yükseliş yaşandığ 1 bir zaman dilimi olarak tanımlanabilir. Doğu Akdeniz bölgesinde Misırlıların liderlik konumunu koruduğu bu dönemde hızlı bir şekilde sanayileşmenin gerçekleştirildiği görülmüştür. Söz konusu dönemde yaygın şekilde dikey dokuma tezgâhı, tarımda pulluk, metalürjide ayak körükleri kullanılmaya başlar. $\mathrm{Bu}$ dönemde kültürel değişimlerin yaşanması kaçınılmaz idi. Dış ilişkilerin gelişmesi Yakın Doğu ülkeleri, daha sonra Yunan kültürü unsurlarının rolünü güçlendirir. Firavun saraylarında özellikle saygıdeğer Suriyeliler büyük bir yer işgal eder. Nitekim mevcut iki saray korosundan biri Suriyelilerden oluşmaktaydı (Gruber, 1941:185). Fakat güçlü ve egemen bir devlet

\footnotetext{
${ }^{5}$ Vurma çalgı

${ }^{6}$ Ölülerin, yeraltı dünyasının ve dirilişin tanrısı

${ }^{7}$ Övgüler ve ağıtlardan oluşan müzikli dramatik gösteriler

${ }^{8}$ Antik Yunan tarihçisi ve yazarı
} 
pozisyonunda olmasına rağmen Girit, Kıbrıs, Ege kıyısındaki diğer çevre devletler, Filistin ve Hindistan'la olan ticari ve kültürel ilişkiler Mısır'ın kozmopolit bir devlete dönüşmesinde önemli bir etken olarak belirlenmiştir. Bu kozmopolitlik devam eden demokratikleşme sürecine eşlik etmekle birlikte, evrensel bağlılığın tehdit edici büyümesi olarak da görülür. Öz-bilinçliliğin ve öz-farkındalığın giderek daha da güçlenmesi sonuçta zorlukları ortaya çıkarır. Böyle bir karşı durma biçimi, yabancı her şeyin fanatik ve hoşgörüsüz algılanması, sanattaki ürkek demokratikleşmenin yanı sıra erotik şarkı sözleri ve benzeri sanat türlerinin gelişmesiyle karakterize edilmektedir (Wilkinson, 2011: 222). Durum böyle olunca toplum giderek eski kültüre, daha kapalı bir kast düzenine ve rahipliğe doğru yön değiştirmeye başlar. Eski kralların kültü yeniden değer kazanmaya, piramitler ve eski anıtlar yeniden yapılanmaya, arkaik metinler anlaşılması zor yabancı kelimelerden temizlenmeye çalışılır. Bu, cenaze şarkılarının bile içeriği belirleyici şekilde değiştirildiği bir dönemdir (Steele, 2009: 50).

Benzer gelişmeler mimari ve görsel sanatlarda radikal değişikliklere yol açar. Bu bakımdan Eski ve Yeni Krallık dönemleri için anıtsallık anlayışının önemli ölçüde farklı olduğu göze çarpmaktadır; Thebes firavunları döneminden başlayarak mimari, heykel, duvar resimleri gibi görsel sanatlarda ihtişamlı ve anıtsal yapıların ruhunu canlandırma çabası görülmektedir (Silverman, 2003:103). Eski dönem mimarisinde anıt modeli olarak mezarlar baskın iken, Yeni Krallık döneminde ekseriya tanrı tapınakları ${ }^{9}$ yapıldığı dikkati çekmektedir. Firavunların kudret ve gücünü simgeleyen bu dev yapitlar hala büyük önem taşımaktaydı. Büyük sütunlar ve kabartmalı süslemelerle kaplanmış duvarlar, boş alanları heykellerle doldurma meyli, bir nevi "restorasyon" havasını açıkça hissettirir. Resim ve heykel sanatı hem biçim hem de içerik olarak köklü değişimlere uğrar. $\mathrm{Bu}$ dönemde kabartma sanatı gelişerek klasik biçim ve eşsiz mükemmellik kazanır. Mısır için bu sanat türünün haklı olarak kültür dünyasında istisnai bir yer tuttuğu ayrıca belirtilmelidir. Zira tapınaklardaki kabartma görüntüleri bize, eski Mısır tarihinin tamamını okumamızı sağlamaktadır. Eski kültüre dönüş yönelimi, politik konuların yansıtıldığı dev kabartmalarda da açıkça öne çıkmaktadır (Kaznelson, 1976: 418).

Aynı kültürel değişimler müzikte de yaşandığı görülmüştür. Sadece yabancı müzik değil, kutsal sistrum hariç dışarıdan gelen çalgılar bile tapınaklardan "kovulur". Eski ezgiler hatırlanarak aynı biçimde yenileri bestelenir. Müzik, "iyi" ve "kötü" olarak ikiye ayrılır, ayrıca ikincisi etkileyici olarak anlamlandırılır (Gruber, 1941: 182). Sürekli askeri seferler nedeniyle, Yeni Krallık döneminde müzik sanatında hemen hemen gelişen tek alan askeri müzik olduğu denilebilir. Zira düzenli ordu ve askeri hayat, müziği de belirli bir düzene sokar. Vurma ve bakır üfleme çalgılardan ordu orkestraları kurulur. Misır müziğinde kromatik ses dizisinin bu dönemde ortaya çıktığı tahmin edilmektedir. "Müzik" anlamına gelen khi sözcüğü, aynı anlamı taşıyan shama/sama terimi ile değiştirilir (Prigarina, 1983: 152). Gelişmiş sosyo-kültürel ortamın yarattığı bu sözde "Mısır Rönesansı" geç Sais döneminden bir süre sonra sona erecektir (Gruber, 1941: 182).

\footnotetext{
${ }^{9}$ Karnak ve Luksor tapınakları
} 
SONUÇ VE BULGULAR

Sonuç olarak, Eski Mısır uygarlığında sanatın önemli bir yer tuttuğu bilgileri ister görsel, isterse de yazılı arkeoloji bulgulardan anlaşılmaktadır. Özellikle görsel kaynaklar yönünden oldukça zengin Mısır kültüründe yaşamın her yönü itinalı bir şekilde betimlenmiştir. Mezar ve tapınak kabartmalarında, duvar resimlerinde önemli tarihsel olgu ve hadiselerin yanı sıra çok sayıda ziyafet sahnesi, müzisyen, şarkıcı, dansçı tasvirleri vardır. Dinsel merasimlerde, kurban ayinlerinde, kutlama törenlerinde, hasat ve ekim zamanı yapılan müzik ve dans eylemlerinin tasviri, Mısırlıların müziğin büyülü güce sahip olduğu hususundaki inancını yansıtmaktadır. $\mathrm{Bu}$ tasvirler, müziğin yaşamda oldukça geniş bir yeri olduğunu söylemekle birlikte dönemin birçok çalgısına da tanıklık eder. Tasvirler sayesinde eski Mısır çalgılarının, belirli müzikal dizilerin ve müziğin yapısının kısmen tespiti mümkün olmuştur. Ayrıca, sanatçılar, özellikle de müzisyenler, Misır toplumunun önemli bireyleri olmuş, toplumda çeşitli rütbelerle farklılık göstermişler. Sanatla sadece erkeklerin değil, kadınların da aktif uğraştığ 1 bir alan olduğu resimlerdeki arp, lir, flüt çalan kadın tasvirlerinden bilinmektedir. Eski Krallık döneminde yaygın kullanılan arp, lir, flüt ve çeşitli vurma çalgıların Yeni Krallık döneminde biçim ve şekil değiştirdiği görülmektedir. Buradan da dönemin müzik zevki ve anlayışının geliştiği ve değiştiği sonucuna varılabilir. Özellikle arp büyük değişiklikler yaşamıştır. Neredeyse insan boyunda olan arpların yanında taşınabilen küçük arp çeşitleri ortaya çıktığı izlenmektedir. Trompet ve obua'ya benzer yeni üfleme çalgı türlerinin ortaya çıkması ise bu dönemde askeri müziğin geliştiğine işaret eder. Eski Mısır kültürünün komşu uygarlıkların gelişiminde de önemli olduğunu kabul etmek için yeterli sebepler bulunmaktadır. Çevredeki uygarlıklar uzun süre Mısır kültüründen etkilenmiş, bu kültür diğer ülke fillozoflarının, şairlerinin, tarihçilerinin gözdesi haline gelmiştir.

Mısır, bilhassa Yunanlar için önemli bilgi membası olmuştur. Yunanların ilk yaptıkları azametli tapınaklar ve heykeller için Mısır bir model oluşturabileceği bu hipotezler arasındadır. Pek muhtemeldir ki, uzun sure Mısır'da yaşayan Pisagor astroloji, müzik, geometri ve matematik dörtlüsünü oluşturan "Quadrivium" teorisini rahip okullarından almıştır (Rojanskiy, 1980: 26-27). Pulver konuyu şöyle yorumlar: "Yunan müziğinde Mısır ölçeği aramak mantıklı gözükebilir. Yunan, kendi kültürünü daha yeni tanıtmaya başladığında, Mısır'da on ikinci hanedanlık rengârenk ve gösterişli müziğinden haz almaktaydı. Bunun yanında dördüncü ve beşinci hanedan dönemine ait müzikal etkinlikleri ispatlayan çok sayıda kanıtlar, Mısır'ın uzun gelişim yolu yaşadığını ifade etmektedir" (1921, 31). Müzik konusunda da Misırlılar Yunan mültecilere çok şey öğrettiler. Büyük olasılıkla Yunanlar, başta tetrakordlar olmakla ileride bütün Avrupa'ya yayılacak kendi müzik sistemlerini de Mısır'dan edinmişler. Bu varsayım, o dönemde onların sıkça gidip geldikleri ve müzik konusunda bilgi alabilecekleri başka bir ülke olmadığı görüşüne dayandırmak mümkündür (Pulver, 1921: 30). Tüm bu söylenenlerden hareketle günümüz modern Avrupa müzik sisteminin beş bin y1l önce piramitler ülkesinden geldiği düşünülebilir.

Araştırma sırasında Krallık Dönemlerinin kültürel unsurları farklı yönleriyle ayrıcalık taşımasıyla birlikte, benzer yönleri de dikkat çekici olmuştur. Yukarıdaki veriler 1şı̆̆ında dönemlerin kültürel özellikleri üzerine bir tartışma noktası oluşturarak bazı açıklamalar yapmak yerinde olacaktır: 
- İlk Çağ uygarlıklarından başlayarak kültürün sihir, büyü niteliğinde olması toplum için önemli bir faktör olmuştur. Eski kültürün kalıntıları sadece müzikte değil, bütün alanlarda adım başı ortaya çıkmıştır. Matem törenleri, şerefe okuma sahneleri, pantomim gösterilerindeki sihir ve büyü karakteri, belirleyici kültürel özelliklerden sayılmıştır. Bu hususiyetler, kesinlikle tüm eski Doğu medeniyetleri için ortak bir görünüm arz etmektedir.

- Genellikle iki koldan gelişen müzik ve sanat, bir yandan zengin ve egemen sınıfın, diğer yandan halkın kültürünü yansıtmıştır. Sınıflar arasındaki farklar onların sanat hayatında da açıç̧a sezilmektedir; Nitekim hükümdarlar için yapılan gösterişli törenlere yüksek performans sergileyebilecek özel yetiştirilmiş müzisyen ve dansçı gruplar katılmıştır. Böyle bir uygulama, farklı sosyal tabakalardan seçilen becerikli tapınak müzisyen ve şarkıcılar müzik pratiğinde bir "demokratikleşme" olgusu olarak nitelendirilebilir.

- İktidar sınıf ve soylular yönetimi sanata ve kültüre büyük değer vermiş, kendi sanatçı kimliklerini ön planda tutmuşlar. Zira yöneten sınıflar toplum içinde önemli bir söz hakkına sahiplerdi. $\mathrm{Bu}$ uygulama, ilkel insanların pratik yaşamlarından süregelmiştir.

Tartışmalar sonucu elde edilen bulgular doğrultusunda, şunu belirtmek gerekir ki, tarih öncesi sınıfsız cemiyetten başlayarak Helenistik dönemin zarif kültürüne kadar Mısır, dört bin yıl boyunca yoğun engellemelere rağmen, kendi kültürünü durmadan geliştire bilmiştir. Bu kültür hem güçlü bir uygarlığın gelişiminde, hem de dünya tarihinin geniş bir kesimi için önemli bir rol oynamıştır. Tüm bu söylenenleri Mısır'daki krallıkların, aradaki çöküş dönemlerine rağmen yirmi yüzyıl boyunca sürdürebildiği başarılar olarak tanımlamak mümkündür.

\section{KAYNAKÇA}

Bard, K, A. (2015). An Introduction to The Archaeology of Ancient Egypt, UK, John Wiley \& Sons

Braudo, E. (1935). İstoriya Muzıki (Sjatiy Oçerk), Gosudarstvennoe Muzıkalnoe İzdatelstvo, Moskva, (2014), Directmedia

Chrıstensen, W. ( 2009). Empire of Ancient Egypt, USA, Infobase Publishing

Denham, T.P., Irıarte, J., Vrydaghs, L. (2016). Rethinking Agriculture: Archaeological and Ethnoarchaeological Perspectives, Routledge, Taylor\&Francis Group, New York

Gadalla, M. (2017). Egyptian Musical Instruments, Second Edition, Tehuti Research Foundation, Greensboro, NC, USA

Grıgorenko, A. (2008). Religii Mira: Slovar-spravoçnik, İzdatelskiy Dom “Piter”, Pİter Press

Gruber, R. (1941). İstoriya Muzıkalnoy Kulturı, Vol.1, I. Çast, Moskva-Leningrad, Gosudarstvennoe Muzıkalnoe İzdatelstvo

Jak, K. (2008). V Strane Faraonov, Geleos Publishing House

Kaznelson, İ. (1976). Kultura Drevnego Egipta, İnstitut Vostokovedeniya, Akademii Nauk SSSR, Moskva, Nauka 
Lexová, I. (2012). Ancient Egyptian Dances, Courier Corporation

Lind Tore T. (2012).The Past is Always Present: The Revival of the Byzantine Musical Tradition at Mount Athos, Scarecrow Press

Massey, G. (2005). Ancient Egypt Light Of The World 2 Vol set, First published in 2005, Routledge is an Imprint of Taylor \& Francis, an Informa Company

Pomeranceva, N. (1976).İskusstvo Drevnego Egipta, İskustvo Drevnego Vostoka. Malaya İstoriya, Vostok, Moskva, Nauka

Pulver, J. (1922).The Music of Ancient Egypt.The Musical Times, Musical Times Publications Ltd.,Vol. 63, No. 948, 127

Prigarına, N. (1983). Sufizm v Kontekste Musulmanskoy Kulturı, Pod Redakciyey Kojukhovoy, A., Moskva, Nauka

Rojanskıy, I. (1980). Antiçnaya Nauka, Moskva, Ripol Klassik

Shındına, N. (2009). Prostoy Sovremennıy Samouchitel İgrı Na Şestistrunnoy Gitare, Moskva, Ripol Klassik

Silverman, David P. (2003). Ancient Egypt Oxford University Press

Steele, Philip. (2009). Ancient Egypt, The Rosen Publishing Group, Inc

Turayev, B. (1935). İstoriya Drevnego Vostoka, Tom 1, Leningrad, Ogiz-Sotsekgiz

Wlkınson, T. (2011). The Rise and Fall of Ancient Egypt, A\&C Black 